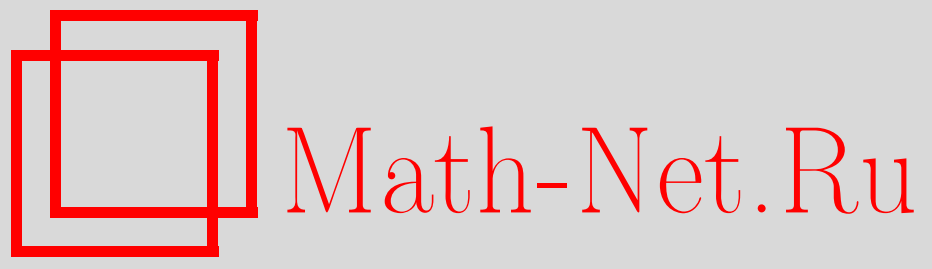

A. M. Kagan, A. V. Nagaev, A lemma on stochastic majorization and properties of the Student distribution, Теория вероятн. и ее примен., 2007, том 52, выпуск 1, 199-203

DOI: https://doi.org/10.4213/tvp16

Использование Общероссийского математического портала Math-Net.Ru подразумевает, что вы прочитали и согласны с пользовательским соглашением

http://www . mathnet.ru/rus/agreement

Параметры загрузки:

IP: 18.208 .226 .222

26 апреля 2023 г., 18:18:46 
6. Деллашери К. Емкости и случайные процессы. М.: Мир, 1975, 192 с.

7. Delarue F., Guatteri G. Weak solvability theorem for forward-backward SDEs. Preprint. Paris: Université Paris-VII, 2005; http://hal.archives-ouvertes/fr/hal00004089/en/.

8. El Karoui N., Mazliak L. (eds). Backward Stochastic Differential Equations. Harlow: Longman, 1997, 221 p. (Pitman Res. Notes Math. Ser., v. 364.)

9. Lepeltier J.-P., San Martin J. Backward stochastic differential equations with continuous coefficient. - Statist. Probab. Lett., 1997, v. 32, № 4, p. 425-430.

10. Meyer P.-A., Zheng W. A. Tightness criteria for laws of semimartingales. - Ann. Inst. H. Poincaré, Probab. Statist., 1984, v. 20, № 4, p. 353-372.

11. Pardoux É., Peng S. G. Adapted solution of a backward stochastic differential equation. - Systems Control Lett., 1980, v. 14, № 1, p. 55-61.

12. Revuz D., Yor M. Continuous Martingales and Brownian Motion. Berlin: SpringerVerlag, 1991, 533 p. (Grundlehren Math. Wiss., v. 293.)

13. Watanabe S., Yamada T. On the uniqueness of solutions of stochastic differential equations. - J. Math. Kyoto Univ., 1971, v. 11, p. 155-167.

Поступила в редакцию 7.IX.2006

(C) $2007 \mathrm{r}$

\author{
KAGAN A.*, NAGAEV A. V.
}

\title{
A LEMMA ON STOCHASTIC MAJORIZATION AND PROPERTIES OF THE STUDENT DISTRIBUTION ${ }^{1)}$
}

Доказана общая лемма о стохастической мажоризации, позволяющая получить нижнюю и верхнюю границы для функции распределения Стьюдента. Обсуждается связь с оцениванием среднего значения нормального распределения посредством доверительных интервалов.

Ключевые слова и фразы: доверительные интервалы, нормальное распределение.

1. Introduction. Let $T_{n}$ be a random variable having the Student distribution with $n$ degrees of freedom,

$$
\mathbf{P}\left\{T_{n} \leqslant x\right\}=S_{n}(x)=\int_{-\infty}^{x} s_{n}(z) d z,
$$

where

$$
s_{n}(z)=\frac{1}{\sqrt{n \pi}} \frac{\Gamma((n+1) / 2)}{\Gamma(n / 2)}\left(1+\frac{z^{2}}{n}\right)^{-(n+1) / 2},
$$

and let $Z$ be a standard normal random variable,

$$
\mathbf{P}\{Z \leqslant x\}=\Phi(x)=\int_{-\infty}^{x} \varphi(z) d z .
$$

In terminology of stochastic majorization (see [3]), $\left|T_{n}\right|$ is stochastically larger than $|Z|$ which, in view of $\mathbf{P}\left\{T_{n} \leqslant 0\right\}=\mathbf{P}\{Z \leqslant 0\}=\frac{1}{2}$, is equivalent to

$$
\mathbf{P}\left\{T_{n}>x\right\}>\mathbf{P}\{Z>x\} .
$$

* Department of Mathematics, University of Maryland, College Park, MD 20742, USA; e-mail: amk@math.umd.edu 
This is certainly a well-known fact. Here a stronger result is proved, namely that $c_{n}\left|T_{n}\right|$ is stochastically larger than $|Z|$, where

$$
c_{n}=\frac{\Gamma((n+1) / 2)}{\Gamma(n / 2)} \sqrt{\frac{2}{n}}
$$

and, moreover, if for a constant $c, c\left|T_{n}\right|$ is stochastically larger than $|Z|$, then $c \geqslant c_{n}$.

One can easily see that $c_{n}<1$.

On the other hand, if $U$ is a positive random variable independent of $T_{n}$ with $\mathbf{E} U \leqslant 1$, then $\left|T_{n}\right| / U$ is stochastically larger than $\left|T_{n}\right|$. The results are related to estimation of the mean $\mu$ by confidence intervals based on a sample from a normal population $N\left(\mu, \sigma^{2}\right)$.

As to the proofs, they are based on a general lemma on stochastic majorization (that may be of an independent interest) and concavity of the standard normal and Student distribution functions on the positive half-line (see [2] for a special case).

2. Results. The following general lemma on stochastic majorization, despite its simple proof, is a useful tool.

Lemma 1. Let $\xi$ and $\eta$ be independent positive random variables with distribution functions $F(x)$ and $G(x)$, respectively. If $F(x)$ is concave for $x \geqslant 0$ and $\mathbf{E} \eta \leqslant 1$, then $\xi / \eta$ is stochastically larger than $\xi$,

$$
\mathbf{P}\left\{\frac{\xi}{\eta}>x\right\} \geqslant \mathbf{P}\{\xi>x\}, \quad x>0 .
$$

The inequality in (4) is strict unless $\eta=1$ with probability one.

$\mathrm{P} \mathrm{r}$ o o f. Due to independence of $\xi$ and $\eta$ one has for $x>0$

$$
\begin{aligned}
\mathbf{P}\left\{\frac{\xi}{\eta}>x\right\} & =\mathbf{E}\left\{\mathbf{P}\left(\frac{\xi}{\eta}>x \mid \eta=z\right)\right\}=\int_{0}^{\infty} \mathbf{P}\{\xi>x z\} d G(z) \\
& =\int_{0}^{\infty}(1-F(x z)) d G(z) .
\end{aligned}
$$

Since $F(z)$ and thus $F(x z)$ is concave for $z>0$, one has due to Jensen's inequality

$$
\int_{0}^{\infty} F(x z) d G(z)=\mathbf{E}\{F(x \eta)\} \leqslant F(\mathbf{E}(x \eta)) \leqslant F(x)
$$

because of $\mathbf{E} \eta \leqslant 1$. Inequality (6) is strict unless $\eta=1$ with probability one. Combining (6) with (5) gives (4). Lemma 1 is proved.

Theorem 1. Let $Z$ and $T_{n}$ be a standard normal and a Student random variable with $n$ degrees of freedom, respectively. Then $c\left|T_{n}\right|$ is stochastically larger than $|Z|$ if and only if $c \geqslant c_{n}$, where $c_{n}$ is given in (3).

$\mathrm{P}$ r o o f. To prove the «if» part, it suffices to show that $c_{n}\left|T_{n}\right|$ is stochastically larger than $|Z|$.

Let $S^{2}$ be an independent of $Z$ random variable such that $n S^{2}$ has the chi-square distribution with $n$ degrees of freedom. As is well known, $T_{n}$ is equidistributed with $Z / S$ and the relation $\mathbf{E} S=c_{n}$ holds (for the latter see, e.g., [1, Chapter 29]). Thus, $c_{n}\left|T_{n}\right|$ is equidistributed with $|Z| /\left(S / c_{n}\right)$. Since $\mathbf{E}\left(S / c_{n}\right)=1$, Lemma 1 implies the part «if».

To prove the «only if» part, let $\Phi(z)$ and $S_{n}(z)$ denote the distribution functions of $Z$ and $T_{n}$, respectively. Set $h(z)=\Phi(z)-S_{n}(z / c)$. Plainly $h(0)=0$ and from (1) one has

$$
h^{\prime}(0)=\frac{1}{\sqrt{2 \pi}}\left(1-\frac{c_{n}}{c}\right)
$$

so that $c<c_{n}$ implies $S_{n}(z)>\Phi(z)$ for $0<z<\varepsilon$ for some $\varepsilon>0$. It means that $c\left|T_{n}\right|$ cannot be stochastically larger than $|Z|$. Theorem 1 is proved.

It is worth noticing that the distribution functions of $Z$ and $c_{n} T_{n}$ are very close in a vicinity of zero (much closer than the distribution functions of $Z$ and $T_{n}$ ). Namely,

$$
\Phi(0)=S_{n}(0), \quad \Phi^{\prime}(0)=\frac{S_{n}^{\prime}(0)}{c_{n}}, \quad \Phi^{\prime \prime}(0)=\frac{S_{n}^{\prime \prime}(0)}{c_{n}^{2}}
$$

and only $\Phi^{\prime \prime \prime}(0)>S_{n}^{\prime \prime \prime}(0) / c_{n}^{3}$. 
Corollary 1. Let $U$ be a positive random variable independent of $T_{n}$ with $\mathbf{E} U \leqslant 1$. Then $\left|T_{n}\right| / U$ is stochastically larger than $\left|T_{n}\right|$.

$\mathrm{P} \mathrm{r}$ o o $\mathrm{f}$. The density function (1) of $T_{n}$ is monotone decreasing on $(0, \infty)$. Thus, the distribution function of $T_{n}$ is concave on $(0, \infty)$ so that the claim follows immediately from Lemma 1.

Relation of Theorem 1 and Corollary 1 to estimation of the normal mean by confidence intervals is discussed in the next section.

3. Confidence intervals for the mean of a normal population. Let $\left(x_{1}, \ldots, x_{n+1}\right)$ be a sample from a normal population $N\left(\mu, \sigma^{2}\right)$. Set

$$
\bar{x}=\frac{x_{1}+\cdots+x_{n+1}}{n+1}, \quad s^{2}=\frac{1}{n} \sum_{1}^{n+1}\left(x_{i}-\bar{x}\right)^{2}
$$

and denote by $z_{\alpha / 2}, t_{n, \alpha / 2}$ the upper quantiles of the standard normal and Student distribution with $n$ degrees of freedom, respectively.

In case of a known $\sigma^{2}$, the interval

$$
\left(\bar{x}-z_{\alpha / 2} \frac{\sigma}{\sqrt{n+1}}, \bar{x}+z_{\alpha / 2} \frac{\sigma}{\sqrt{n+1}}\right)
$$

is a confidence interval for the mean $\mu$ of confidence level $1-\alpha$.

In case of an unknown $\sigma^{2}$, the interval

$$
\left(\bar{x}-t_{n, \alpha / 2} \frac{s}{\sqrt{n+1}}, \bar{x}+t_{n, \alpha / 2} \frac{s}{\sqrt{n+1}}\right)
$$

is known as the Student confidence interval for $\mu$ of level $1-\alpha$.

The mean length of $(8)$ is

$$
2 t_{n, \alpha / 2} \frac{\mathbf{E} s}{\sqrt{n+1}}=2 t_{n, \alpha / 2} \frac{c_{n} \sigma}{\sqrt{n+1}}
$$

versus the (constant) length of $2 z_{\alpha / 2} \sigma / \sqrt{n+1}$ of (7).

The «if» part of Theorem 1 is equivalent to that for all $\alpha, 0<\alpha<1$,

$$
c_{n} t_{n, \alpha / 2}>z_{\alpha / 2} \text {. }
$$

Indeed, the fact that $c_{n}\left|T_{n}\right|$ is stochastically larger than $|Z|$ means that for all $x>0$,

$$
\mathbf{P}\left\{c_{n} T_{n}>x\right\}>\mathbf{P}\{Z>x\}
$$

or, equivalently, $S_{n}\left(x / c_{n}\right)<\Phi(x)$. The latter inequality is equivalent to that for all $\alpha$, $0<\alpha<1$

$$
S_{n}\left(\frac{z_{\alpha / 2}}{c_{n}}\right)<\Phi\left(z_{\alpha / 2}\right)=\frac{\alpha}{2}=S_{n}\left(t_{n, \alpha / 2}\right)
$$

whence (9).

The fact that (8) is in average wider than (7) is known (see, e.g., a problem in $[4$, Chapter 7]) so that its connection to Theorem 1 is of a methodological interest.

Let us now look at the interval (8) and its potential competitors. The Student's idea can be implemented in different ways. One of the natural alternatives to (8) is the following. Take a statistic

$$
d=\frac{a_{n}}{n+1} \sum_{1}^{n+1}\left|x_{i}-\bar{x}\right|,
$$

where $a_{n}$ is a constant, and proceeding à la Student, form a quasi-Student ratio $R_{n}=$ $\sqrt{n+1}(\bar{x}-\mu) d^{-1}$ whose distribution function $Q_{n}(x)$ does not depend on the parameters $\mu, \sigma^{2}$. Let $q_{n, \alpha / 2}$ be the upper quantile of order $\alpha / 2$ of $R_{n}$. The interval

$$
\left(\bar{x}-q_{n, \alpha / 2} \frac{d}{\sqrt{n+1}}, \bar{x}+q_{n, \alpha / 2} \frac{d}{\sqrt{n+1}}\right)
$$

is a confidence interval for $\mu$ of level $1-\alpha$. 
Notice that the interval (10) does not depend on the choice of $a_{n}$; for the purpose of comparing (10) with (8) it is convenient to choose $a_{n}$ such that

$$
\mathbf{E} d=\mathbf{E} s=c_{n} \sigma .
$$

The mean length of $(10)$ is $2 q_{n, \alpha / 2} c_{n} \sigma / \sqrt{n+1}$.

The Rao-Blackwellization of (10) leads to

$$
\left(\bar{x}-q_{n, \alpha / 2} \frac{s}{\sqrt{n+1}}, \bar{x}+q_{n, \alpha / 2} \frac{s}{\sqrt{n+1}}\right)
$$

with the same mean length as (10). Indeed, as functions of the residuals $\left(x_{1}-\bar{x}, \ldots\right.$, $\left.x_{n+1}-\bar{x}\right)$ the pair $(d, s)$ is independent of $\bar{x}$ so that

$$
\mathbf{E}(d \mid \bar{x}, s)=\mathbf{E}(d \mid s) .
$$

Furthermore, due to (11), both $d$ and $s$ are unbiased estimators of the same parametric function. Thus, by virtue of completeness of the sufficient statistic $(\bar{x}, s)$ for $\left(\mu, \sigma^{2}\right)$,

$$
\mathbf{E}(d \mid s)=\mathbf{E}(d \mid \bar{x}, s)=s .
$$

Hence proving that the mean length of (8) is for all $\alpha, 0<\alpha<1$, less than the mean length of (10) is equivalent to proving that $\left|T_{n}\right|$ is stochastically smaller than $\left|R_{n}\right|$. We shall prove a more general result dealing with confidence intervals of the form

$$
\left(\bar{x}-m\left(\left|x_{1}-\bar{x}\right|, \ldots,\left|x_{n+1}-\bar{x}\right|\right), \bar{x}+m\left(\left|x_{1}-\bar{x}\right|, \ldots,\left|x_{n+1}-\bar{x}\right|\right)\right),
$$

where $m\left(y_{1}, \ldots, y_{n+1}\right)$ is a positive homogeneous function of order of homogeneity one, i.e., for any $\lambda>0$,

$$
m\left(\lambda y_{1}, \ldots, \lambda y_{n+1}\right)=\lambda m\left(y_{1}, \ldots, y_{n+1}\right)
$$

Plainly the intervals (8) and (10) are of this form. Other examples are intervals corresponding to

$$
m\left(y_{1}, \ldots, y_{n+1}\right)=\text { const }\left(\sum_{1}^{n+1} y_{i}^{p}\right)^{1 / p} \quad \text { for any } p>0 .
$$

If $m\left(y_{1}, \ldots, y_{n+1}\right)$ is homogeneous of order one, then $m\left(\left|x_{1}-\bar{x}\right|, \ldots,\left|x_{n+1}-\bar{x}\right|\right)=$ $s m\left(\left|x_{1}-\bar{x}\right| / s, \ldots,\left|x_{n+1}-\bar{x}\right| / s\right)=s m(U)$, say. Recycling above notation, set

$$
R_{n}=\frac{\sqrt{n+1}(\bar{x}-\mu)}{\operatorname{sm}(U)}
$$

and denote by $Q_{n}(x)$ the distribution function of $R_{n}$. Due to the structure of $R_{n}, Q(x)$ does not depend on $\left(\mu, \sigma^{2}\right)$ and, moreover, $Q(x)=1-Q(-x)$. Let $q_{n, \alpha / 2}$ denote the upper quantile of order $\alpha / 2$ of $Q$. The interval

$$
\left(\bar{x}-q_{n, \alpha / 2} \frac{s m(U)}{\sqrt{n+1}}, \bar{x}+q_{n, \alpha / 2} \frac{s m(U)}{\sqrt{n+1}}\right)
$$

is a confidence interval for $\mu$ of level $1-\alpha$.

Without loss in generality, one may assume $\mathbf{E}(m(U))=1$ since multiplying $m(U)$ by a constant $c$ results in that the new quantile will be $q_{n, \alpha / 2} / c$ so that the multiplication does not affect (13). implies

Since $s$ and $U$ are independent (for samples from a normal population), $\mathbf{E}(m(U))=1$

$$
\mathbf{E}(\operatorname{sm}(U))=\mathbf{E} s .
$$

Theorem 2. The mean length of (13) is never less than that of (8),

$$
2 q_{n, \alpha / 2} \frac{\mathbf{E}(s m(U))}{\sqrt{n+1}} \geqslant 2 t_{n, \alpha / 2} \frac{\mathbf{E} s}{\sqrt{n+1}},
$$

the equality sign in (14) holding only when $m(U)=1$ with probability one (in which case $\left.q_{n, \alpha / 2}=t_{n, \alpha / 2}\right)$. 
$\mathrm{P} \mathrm{r}$ o o f. It suffice to show that for all $\alpha, 0<\alpha<1$,

$$
q_{n, \alpha / 2} \geqslant t_{n, \alpha / 2}
$$

with the equality sign holding only when $\mathbf{P}\{m(U)=1\}=1$. The vector $\left(\left(x_{1}\right.\right.$ $\left.\bar{x}) / s, \ldots,\left(x_{n+1}-\bar{x}\right) / s\right)$ of the Studentized residuals is an ancillary statistic (i.e., its distribution does not depend on the parameters $\left.\left(\mu, \sigma^{2}\right)\right)$ and hence is independent of the complete sufficient statistic $(\bar{x}, s)$ (a special case of Basu's theorem). Thus, $\sqrt{n+1}(\bar{x}-\mu) / s$ is independent of $m(U)$. The random variable $\sqrt{n+1}(\bar{x}-\mu) / s$ is distributed as $T_{n}$ while $\mathbf{E}(m(U))=1$ so that Corollary 1 implies that $\left|R_{n}\right|$ is stochastically larger than $\left|T_{n}\right|$ whence (15). As in Lemma 1, the equality sign in (15) holds only if $m(U)$ is constant with probability one, and the constant is necessarily 1, due to the assumption $\mathbf{E}(m(U))=1$. Theorem 2 is proved.

Acknowledgment. The work began in May 2004 during A. V. Nagaev's visit to Department of Mathematics, University of Maryland. In February 2005 Alexander Nagaev died in a downhill skiing accident. He was a good friend for some fifty years, since the time when we both were students at University of Tashkent.

\section{СПИСОК ЛИТЕРАТУРЫ}

1. Крамер Г. Математические методы статистики. М.: Мир, 1975, 648 с.

2. Kagan $A$. What students can learn from tables of basic distributions. - Internat. J. Math. Ed. Sci. Tech., 1999, v. 30, №6, p. 928-934.

3. Маршалл А., Олкин И. Неравенства: теория мажоризации и ее приложения. М.: Мир, 1983, 574 c.

4. Shao J. Mathematical Statistics. New York: Springer-Verlag, 2003, 591 p.

Поступила в редакцию

17.I.2006 